\title{
Management of e-Technology in China
}

\author{
Yi Wei ${ }^{1}$, Sirp J. De Boer ${ }^{1}$, Jin Chen ${ }^{2}$ \\ ${ }^{1}$ Section International Business Management, Faculty of Technology \& Management, \\ University of Twente, P.O.Box 217, 7500 AE Enschede, the Netherlands \\ ${ }^{2}$ College of Management, Zhejiang University, Hangzhou, 310027, P.R. China
}

\begin{abstract}
The "e" technology is bringing about many challenges for companies, in particular for their managers. This concerns a vast range of business processes in many sectors of the economy and in nearly every country of the world. In rapidly industrializing China companies and other organizations are actively finding their way by adapting, developing and exploiting new e-technologies. The paper's focus is the identification of the management issues in implementing etechnology in China. The paper reports on research into difficulties of establishing and operating e-business in China. In particular, it discusses management related to e-technology sharing and application. A brief review of literature is followed by the analysis of three recent case studies: an international IT services alliance, a financial services provider and an international manufacturing joint venture. All case companies are applying e-technology in China, but the role of e-technology differs in the three cases: adding a service line to the existing business processes, developing a new business process and increasing efficiency and effectiveness in business processes. The conclusions present the emerging management issues: cooperation is a key asset in networking; the choice of business models plays an important role; adequate management attention for details such as training program is required.
\end{abstract}

\section{INTRODUCTION}

The technological evolution has exploded into an " $e$ " revolution. IT systems have become more user friendly, and dramatic gains in return on investment (ROI) appear achievable [26]. Many companies need to put the " $e$ " technology revolution into perspective in order to meet the challenge created by today's rapidly changing IT business environment. Not only is it imperative for traditional companies to become e-business-enabled, it is critical that these companies devise a careful plan to manage convergence, based on the contemporary knowledge of the compatibility and survivability of technology options. However, the period of "e revolution" as just another stage (however dramatic) in the inevitable migration of traditional business structures into the new e-business business paradigm based on an IT platform. The real issue is not e-commerce, but the effective management of the traditional business and emerging IT models into a new e-business structure. The key is to put the problem into proper perspective, integrate evolving IT into a new e-business model, and manage the transition from the old brick and mortar structure into the new IT based e-business of the future [26].

E-business systems today are built using many different technologies such as Microsoft's Site Server Commerce
Edition, IBM's Net.Commerce, Lotus Notes and Domino, Java, IBM WebSphere, and IBM MQSeries. These e-business applications are also hosted on many platforms including Unix, NT, AS/400 and S/390. Here, e-technology is defined as the architecture, technologies and components that enable and support e-business. Using e-technology, businesses can build cost-effective, high-value e-business solutions that scale with their needs and integrate with existing systems. Effective e-business technology has to deliver a coherent, scalable architecture that can handle the complete range of ebusiness and enterprise solutions.

China is industrializing rapidly and the development of e-business receives a lot of attention. At the same time, there are a number of special hurdles that have to be overcome when applying e-technology in this country. The core question of this paper is:

\section{What are management issues in implementing $e$ - technology in China?}

In order to arrive at an answer to the question the paper will describe the results of a literature survey as well as of three case studies. The review of literature highlights the enormous growth of personal computers and Internet and China and the ensuing potential. The method used to analyze the cases is to first describe the main characteristics of the case. From the different descriptions a number of management issues are derived. Next, the case results are compared and discussed in order to arrive at more general issues presented in the conclusions.

The first case study concerns the promoting of the etechnology to the Chinese market by a small Dutch company Tradeview B.V and its Chinese business partner Rayes. The second case study describes how Chinese IT company-Xunda Infolink Information Technology Co. Ltd succeeded by adapting the e-technology and became a leader in ecommerce and $m$-commerce in financial service field in China. The third case study discusses the implementation of the e-technology--ERP (Enterprise Resource Planning) package in a foreign invested enterprise Mitsubishi (Guangzhou) Compressor $\mathrm{Co}$, and its potential for further ecommerce application.

\section{E-COMMERCE IN CHINA}

The subject of E-commerce in China is a challenging one. On the one hand, this country offers enormous potential 
business opportunities, while on the other hand there is quite a range of obstacles that affect its development. Developing E-commerce in China would be a colossal project requiring the telecommunication/Internet infrastructure; market development; new laws, policies and technical skills; and international cooperation.

During the 1990s', China's rapid economic growth has impressed the world. The Chinese government believes that development of the Internet and installing telecommunications lines throughout the country could benefit the population by enhancing their productivity and buttressing the country's economic reforms. Its telecommunications sector was and is undergoing a major transformation. As a result, the telecommunication sector in China has been growing faster than the economy as a whole and has been expanding at an annual rate of $30-50 \%$. The number of fixed-line telephone users in China reached 111 million in 1999, and the total number of mobile communications network subscribers has exceeded 40 million in 1999 and it is expected to exceed 75 million in 2000 (refer to figure 1) [1] [2]

Large progress in IT industry also has been made during the past decade, for instance, in PC sales in China, which has shown a strong increase (refer to figure 2) [23].

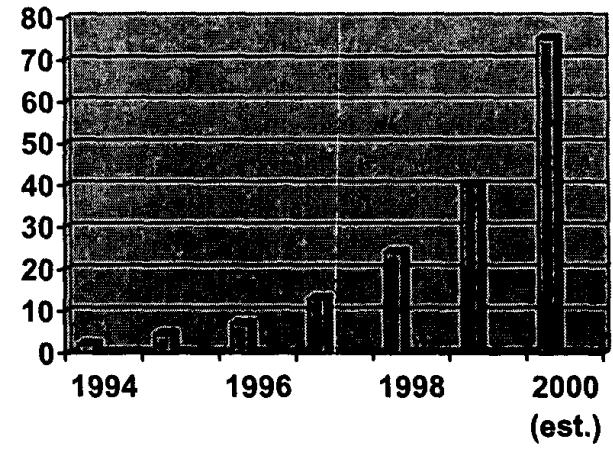

Figure 1: China's Mobile Phone Users (in millions) Source: China Mobjle Communications

With its telecommunication and IT infrastructure, China has taken a major step in becoming an important part of the global Internet economy. The Internet in China is designed to help vendors, service providers, media companies, financial institutions and other market players to profit from its emerging Internet market. According to CNNIC (China Internet Network Center) reports, some major Internet developments can be seen as below figure 3 :

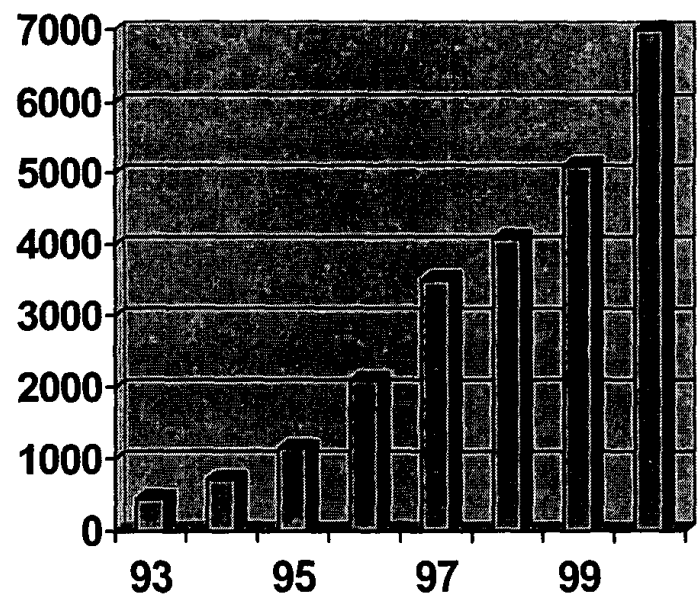

Units (in 000)

Figure 2: Annual Sales of PC's in China 

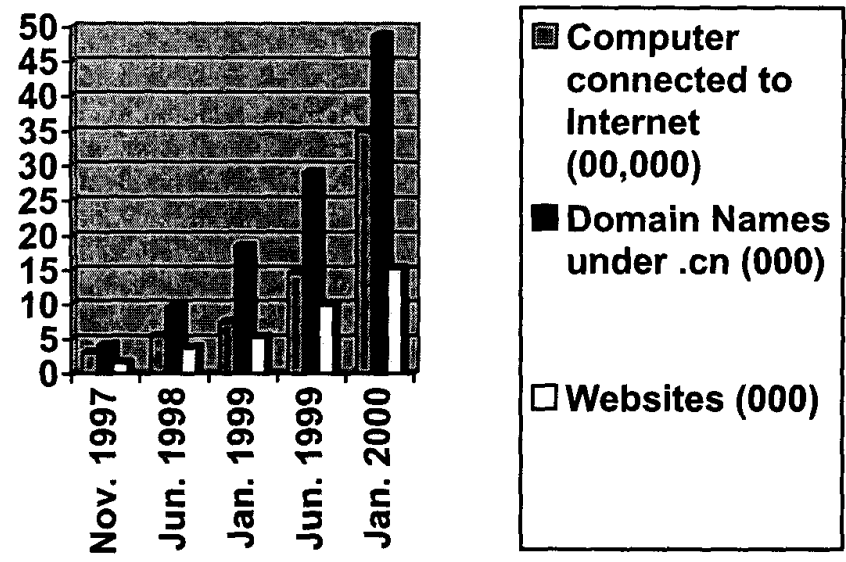

Figure 3: Internet Development in China Source: CNNIC

The growth of Internet users in China is dramatic and the number almost doubled every six months during the last three years. According to the newest report by CNNIC, the total number of online users has reached 16.9 million by the end of June 2000 . While Internet users currently account just more than $1 \%$ of the population, China's Internet user base is expected to grow to 30 million by the end of year 2000 , making it the second largest Internet market in Asia. By 2005, Internet users in China are expected to reach 85 million or more than $37 \%$ of the Asian Internet user market (Refer to figure 4). However, other observers have doubted these numbers of online users in China. International Data Corporation (IDC) reported 5.37 million Internet users in China by the end of 1999, and it expected the number to exceed Japan in 2002, to give China the top spot in Asia [3].
The Yankee Group in the US, says that China will have more users than any other Asia-Pacific nation by 2001, with about 40 million people online; and by 2005 , it should surpass the U.S. and have the most Internet users in the world [19]. However, among those arguments, one fact is they all hold a positive view of China's Internet usage outlook and that China will be one of the leaders in the world Internet marketplace. In addition, China has approximately 80 million Cable TV subscribers and about 300 million TV sets in use. Experts argue that lower prices for PCs, the high rate of government investment in telecommunications, the increasingly competitive ISP (Internet Services Provider) and ICP (Internet Contents Provider) market, and the low-cost and fast access through TV cable becoming widely available, will help spur the growth of China's online population.

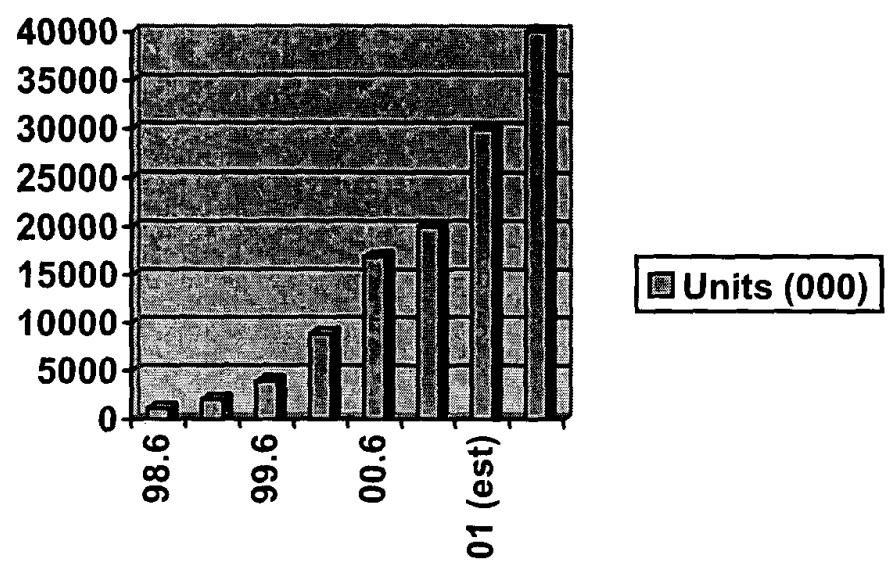

Figure 4 Internet users in China (from 98.6 to 2002) Source: mainly from CNNIC's reports 
Early-moving international and Chinese players are investing in the potential of e-commerce to transform China's geographically distinct, complex markets into one emarketplace. The Chinese Government also clearly strengthened its support and its efforts to co-ordinate this growth of e-commerce.

The powerful Chinese official agency MII (Ministry of Information Industry) published that China's e-commerce web sites had combined revenues of RMB 200 million (US\$ 24.2 million) in 1999 , or twice as much as in 1998. Ecommerce in China will enter a period of rapid growth beginning in 2002 so that China's total e-commerce revenue will reach RMB 800 million (US\$ 96.7 million) by the end of 2000 and RMB 10 billion (US\$ 1.2 billion) by the year 2002 [4]. E-commerce is also spreading quickly from China's coastal regions to its interior and from big cities to small and medium-sized ones [5]. However, several weaknesses are still remaining and still need long time to be overcome. In short, for the future development of China's E-commerce there are a number of critical issues.

(1) The current state of IT infrastructure, required for conducting E-commerce, is rather poor. Government is well aware of this and inducing state-owned companies to invest in improvements, but investment requirements are huge.

(2) Internet usage is increasing quite rapidly, not only among, ICPs, and consumers but also among companies. B2C E-commerce is hampered by poor basic facilities (payment, delivery). B2B is still in a very early stage of development. Substantial increase of the application of E-commerce depends on the development of related services and juridical regulations.

(3) Even though English currently is widely used in Ecommerce, the use of Chinese is expected to increase in the coming years.

(4) China's entry into the WTO (World Trade Organization) is expected to have a positive impact on the development of E-commerce (IT-infrastructure and business opportunities); however, much depends on the implementation of the agreement.

(5) The ambiguous attitude of the Chinese Government constitutes a serious factor in E-commerce and Internet development. The potential economic gains have to be balanced against the potential political consequences of free flow of information [25].

\section{CASE A-CHINAVIEW}

\section{A. The partners}

Tradeview B.V. (below referred to as Tradeview) is a small IT company that was founded in 1995 by an entrepreneur who moved from computer hardware field to the software sector. Currently, there are 15 employees working in its head-office located in Enschede, the Netherlands for the European market.
Tradeview is small, but aiming to go global, especially to the Far East. In 1998, the founder of Tradeview realized that China, which is one of the fastest developing economies and Internet markets, could be a huge potential market for Tradeview's products. However, due to lack of the resources and experience, Tradeview cannot do it alone and it must find suitable partner(s) to develop the market together.

Shenzhen Rayes Group Co., Ltd. (below referred to as Rayes) is a Hi-Tech shareholding enterprise specialized in ISP operation and related technical support. It started operation in Oct. 1995, and the registered capital is US $\$ 23$ million. By the end of 1999 , its operations covered 108 cities and provinces in China, the total assets US $\$ 240$ million, and the number of employees was 2,360. Their main services include ISP, ICP, IPP (Internet Phone Provider), Intranet, and I-fax, etc.

\section{B. The Technology}

Tradeview has developed extremely user-friendly etechnology software named Tradeview/Easyview to quickly create a professional web-site page complete with picture and text, search friendly databases, which it offers to companies and individuals for presentation of their products and services on the Internet. From their point of view, EasyView/TradeView supplies the most innovative software available worldwide, and there is no product on the market today that competes directly with its products, while its products' simplicity and accessibility are expected to attract large numbers of customers from many business sectors. The current and potential customers of Tradeview/EasyView in Holland (Dutch/English version) mainly consist of ISPs (Internet Services Provider), publishers, advertisers, manufacturers, trading houses, and some sports clubs (see details at Tradeview homepage-customers).

This colorful online method Easyview is a software program based on five logical steps. In a simple and straightforward manner, it enables the user to place graphics, text and keywords on professional WebPages in less than a few minutes and the user or advertiser can create and update those pages at any time without having advanced computer or networking knowledge. Tradeview is a database (server software) used in combination with Easyview. The software module automatically deals with all the pages and arranges them into internal search machines, websites, catalogues and portals. Once a web page is ready for distribution, a simple push of a button sends the page with a number of keywords to a global Internet guide and there is no limit to how often and how many pages can be changed or updated. The integrated interactive marketing methods as for E-commerce etc. can be linked to various payment systems. Moreover, apart from English, all other languages can be integrated [21].

\section{Application in China}

As mentioned before, Tradeview wants to enter China's market. After spending several months for searching and 
negotiating, Tradeview and Rayes had agreed to set up an alliance to market Tradeview/Easyview products into Mainland China. The agreement a cooperative venture between Tradeview and Rayes dated November 24, 1999, specified that, TradeView would develop the new product (Chinaview), and transfer the technical knowledge for the new venture. Rayes would provide capital for financing the operation equipment and office in Shenzhen (where the new venture locates), and is responsible for looking for the potential customers by using its current business network ChinaOnline $(C O L)$. Furthermore, Rayes would recruit employees for the new venture. ChinaView is based on its product-Tradeview/EasyView, but the original languages of the product are Dutch and English. To meet with the requirements of Chinese customers, it should be changed to Chinese/English. Moreover, Chinaview is a product for Chinese customers who are different from Tradeview's current customers in Europe. The potential customers for Chinaview include ISPs, publishers, Government, wholesalers, industrial associations, and big manufacturers. In details the requirements of Chinaview include:

Chinese and English: all pages have Chinese and English versions. Visitor around the world can choose Chinese or English to view the pages. Though Chinaview is written in simplified Chinese, it also can be used to make traditional Chinese pages that are also suitable for Taiwan and Hong Kong markets.

Technically easy for use: customers can make professional pages in a few minutes and every task can be done with only five-color buttons on the web. It is easy to learn and people without any PC and Internet knowledge can use it.

Multiple functions, and flexibility and interaction: the web pages created by ChinaView have completely automatic content management, automatic administration and control. Customers can make changes at any time and as often as they like at zero additional cost.

Cheaper price: by aiming at the huge potential customer base and the market condition, the price of Chinaview should be much cheaper than Tradeview/Easyview in its home country/Europe.

\section{Cooperation}

The cooperation between Tradeview and Rayes was started from 1998, and the details of their cooperation as follows:

1. The initial contact and negotiation period (1998-mid 1999)

At this stage, the contacts between both companies were based on the discussion of product/technology requirement, market condition, and cooperation items including financial, staffs, structure, and the responsibilities. They did not have any relation before they started contacting, and the result was that communication did not run smoothly. To overcome the cultural barrier, Tradeview employed a Chinese MBA graduate from TSM Business School, the Netherlands, to act as the China project manager. Since then, the communication between the two sides was much easier.

2. The innovation/improvement period (mid 1999-end of 1999)

Based on their agreement that had been signed at the previous stage, the major task at this stage is development of the new product--Chinaview. Tradeview spent several months in employing a number of programmers to complete it as soon as possible, and by the end of 1999 , the job had been done.

3. The operating period (Jan. 2000 until now)

Since the new product-Chinaview had been developed the operating process was on track. The operating center is set in Shenzhen where the Rayes headquarter is located, and some staff was transferred from Rayes to this venture. Tradeview hired another Chinese MBA graduate who also gained his degree in the Netherlands to be its representative to work with that team.

\section{E. Opposing Views}

Now that both partners have been operating for almost one year, there is a deadlock situation in the cooperation between the two parties. Based on several interviews with both parties, the problems and complains can be summarized as below.

From Tradeview's point of view, the main problems of the unhappy marriage with Rayes are:

(1) Rayes is financially and technically weak in promoting Chinaview, while Tradeview is unwilling to input more investment (it cannot finance an independent working team that they do need in China without having gained profit from the business based on its financial shortage).

(2) The management team of Rayes is poor in terms of leadership and employees' quality and loyalty, and also lacks proper understanding of the product and market.

(3) The geographical distance makes the communication between the two parties weak.

(4) The cooperation period has been set for 5 years, and Rayes acts as Tradeview's only agent in China. However, nothing guarantees that the distributor will posses the corporate culture appropriate to a slow cashflow cycle.

(5) Rayes has offices in more than 100 cities around China, but it only actively engages its office in Shenzhen (Guangdong), which means Rayes is just targeting the product at the Guangdong province rather than nation wide. However, Beijing and Shanghai as the two major cities/regions count almost half of the online users and websites in China. Therefore, the scope of the current marketing strategy is too narrow. 
Rayes blames Tradeview on the following points:

(1) The communication with Tradeview is very difficult even though Tradeview had hired a contact person in China and there is another Chinese MBA graduate in Tradeview's head-office in Holland.

(2) Within Rayes, there is not much money available to market Chinaview product and Tradeview refused to invest as well. In addition, the e-market in China is still small and the transportation system is still poor, and it requires hard working and efforts.

(3) The target customer group for the Chinaview project is SMEs (small and medium sized companies) since big companies already have the 'electronic' people to make their own websites but SMEs lack for capital and experience to do so. But Tradeview is always aiming at the large firms.

(4) The Chinaview product only makes use for Simplified Chinese and English although Tradeview had promised that the product could be used under Traditional Chinese system as well. Therefore, it can not be applied to other areas like Hong Kong and Taiwan, which are using Traditional Chinese system, narrowing the market scope.

(5) For the protection reason, Tradeview does not provide the program source codes to Rayes and just did some training for Rayes' technicians. There have been some technological problems but as Rayes did not get the technical support from Tradeview, the demand/requirement of the users cannot be met quickly.

(6) Rayes sees the IP Fax and IP Phone as its priorities for the business activities, giving the opportunity to 'touch' their clients monthly and closely when they use the services. They are willing/had started to add Chinaview to this product package and currently a group of 1,000 IP Fax/Phone clients already received the Chinaview product. Tradeview will get a certain share from the income of the package sales. However, Tradeview hesitates for such idea and never responded to Rayes' plan.

\section{F. Discussion}

The success of strategic relationships is driven by both structural elements and social elements [24]. Selecting appropriate partner is the most important issue in forming strategic alliance. However, many scholars have found out that the key issue in partner selection is to assess the degree of possible fits to the other partner's profile [15] [14] [12] [16]. Therefore, we use the strategic, resource, cultural, and organizational fits to measure the target business cooperation.

Klofsten and Scharberg [18] state that the barriers between small and large IT firms can be divided into three types: differential interests, resources and size; differential assets, secrecy and trust; and cultural differences and communication problems. From above analysis, those barriers all can be found from Tradeview and Rayes case.
At the first grace, the sizes unbalance and the different strategic importance of their Chinaview project have shown there is no sufficient strategic fit between the two parties, even though both parties have provided their core competences----Chinaview product and business network in China. However, since Rayes sees Chinaview as just one additional product besides its own services, and it will not commit its whole business network and resources to support this project.

Although China is one of the fastest growing nation in the World in Internet development, its market conditions are still under-developed. Most potential customers lack IT experience and knowledge; promoting the Chinaview product in China's market successfully requires large amounts of investment in advertisement and even in pre-education of end users. At this point, Tradeview is too small in size and too weak in its own financial sources, while Rayes is not willing to provide the necessary investment either unless the project belongs to its own business priority and the partner provides the same amount as it does. Therefore, the resource gap leads the cooperation running difficult and slow.

Tradeview had prepared well for overcoming the cultural difference with its Chinese partner. To do so, it had employed two Chinese MBA graduates who gained their degrees in Holland and had strong knowledge in understanding the Dutch and Chinese cultural difference, and located one in China and one in its head-office in Holland. However, in practice, the cultural gap and communication problem is still remaining, and it results in a total lack of tnust between the two partners.

The alliance design in this case is simple. Due to the low strategic fit between the two parties, the bargaining position imbalance is quite distinct: which Rayes takes more power and control in the alliance. Such a situation will endanger the cooperation stability. In addition, since the daily communication between the two partners is via the electronic form such as email, fax and telephone, the cooperation form is more like the currently widely discussed Virtual Organization (Alliance) form [10]. In such a form, the base or the heart is trust. The benefits of a trust-based relationship tend to be long-term, whereas benefits of acting untrustfully tend to be short-term [13].

\section{G. Conclusions}

Neither Tradeview nor Rayes had expected the alliance to stand at such a situation and they are considering ending the cooperation or changing its form. The main management issues emerging from this case study are:

(1) The difference in size of the two partners implies a barrier. However, this obstacle can be overcome but would require the larger partner to take the lead [17].

(2) The strategic fit was not as good as it could have been: for the Chinese partner the new product constituted merely an additional service for a limited segment of the market, while the foreign partner aimed at penetrating the Chinese market rapidly. 
(3) The operational business methods do not match: the foreign partner expects quick payments of sales while the Chinese partner's operating systems do not easily provide the required information and settlement.

(4) Cultural differences continued to play a role, but are particularly persistent because of insufficient trust, which relates to the previous issue. Developing jointly a set of conflict resolution techniques will enhance the cooperation

\section{CASE B-YESTOCK.COM}

\section{A. The Company}

Shenzhen Xunda Infolink Information Technology Co. Ltd (below refer to Xunda) is a leading software developer in securities e-commerce in China. It is the main operator of the biggest online Securities Platform in China--Yestock.com. This company was established on May 1996 with registered capital RMB 1 million and the total number of employees now is more than 200 compared with only 3 at the beginning. Since then, it has built strategic partnerships with more than 40 securities brokerage companies and other institutes in China. So far, it has more than 500 enterprises (mainly securities brokerage companies) and 500,000 individual customers, and the turnover of its software was 10 million RMB in year 1998. Its more than 30 software products can be grouped into three categories: Internet family, Extranet family and Intranet family.

www.yestock.com (China Securities Commerce Net) was established by Xunda in August 1999. It is a portal web-site where customers/stock investors can do all actions related to the stock exchange in China through PC, phone, Fax, WebTV, Pager and so on by using its network with local ISPs, banks, telecom, financial information providers, call centers, and brokerage companies. Its services are based on Internet and integrate with other electronic channels.

The main services are as follows:

- Real time indexes information and stock quotes of Shanghai Stock Exchange and Shenzhen Stock Exchange

- Experts' analyses and recommendations

- Professional brokers' Q\&A service

- Financial information services through electronic channels such as Pager, voice box, mobile phone, e-mail

- Virtual stock investment community

- Professional assets management

At July 27, 2000, Yestock ranks the No. 1 among the financial web-sites in China by CNNIC less than 1 year after it just started operating. And the number of page-views exceeded 90 million by September 2000 with 500,000 daily page-view counts. The monthly total value of online stock exchange through its web-site is already over 3 billion RMB, and the monthly revenue is around RMB 3 million. According to the CEO Zhu Zaiguo, the turnover will top 100 million next year and the company will reach breakeven in June or July 2001 [6].

In August 22, 2000, the leading PC producer in China Legend decided to invest 35.37 million US\$ of tangible assets into Yestock to exchange 54.34 million ( $40 \%$ ) of Yestock's shares.

\section{B. The Technology}

Even though the e-commerce is still a hot topic in the current Internet business environment. Yestock sees the $m$ commerce as an expansion of its e-commerce strategy, which could help the company to continuing success in China's emarketplace. The STK is the key m-technology for Yestock to move its business scope to $\mathrm{m}$-commerce from e-commerce. The STK is a card that GSM users just need to put inside their mobile phone. Then they can get and exchange information through the mobile phone. Compared with other ways such as Pager and WAP, the STK technology has its advantages. For instance, information through Pager only has one way. And the real time index information through WAP takes almost 3 minutes to renew once, but it can be done every second while through STK. Also, the buying price of a STK card is much cheaper a WAP. The new e-technology STK service has provided opportunity for it to move rapidly [7].

\section{Application}

At their e-commerce model, Yestock is acting as a third party, which can be called a virtual broker between stock investors and the brokerage companies [10]. Investors can obtain much information related to the stock market such as quotes, indexes, analyses, and financial news and so on by using PC via Internet. Then they open accounts in selected brokerage companies to place their orders. The transaction process can be done online (via Internet) or offline (by phone, $f a x, e t c)$. This model can solve some typical problems such as the trust and payment as we stated in the prior part (see Ecommerce in China).

The m-commerce model is an expansion based on its ecommerce model. The users who also have the STK card can access and exchange information through their mobile phones. The transaction process also can be done via their mobile phones. However, in such model, Yestock is still acting as the third party.

\section{Challenges}

(1) Internet user base: According to the CEO of Yestock, China has around 20 million Internet users now, but most of the users are students or income less than RMB 2000 per month. It is hard for an online company to make profit through e-commerce so far comparing with other countries such as U.S., Japan. For instance, many market observers have stated that as a whole market, dot.com companies could reach breakeven point when the online user base accounts 20 million. However, the story in 
China could be different, which the base should be around 100 million (Yestock materials).

(2) The rapid mobile expansion: China had made large progress in telecommunication development. Currently it has more than 43 million mobile phone users and the number will reach 75 million in short term (refer to figure 1). In addition, most of those GSM mobile users are entrepreneurs, managers, or persons who have medium/high income. Therefore, the size and ability of spending and investment of this group are much stronger than Internet users.

(3) The rapid stock investment expansion: although the stock exchange in China is still young (started from 1988 and only eight stocks were traded in Shanghai Stock Exchange with the total market value around 100 million $R M B$ ), however, the market expansion has surprised the world. During the past decade, the total market value of the two stock exchanges doubled every year, and the number of registered stock investors increased $94.8 \%$ per year and currently there are more than 45 million investors in China. However, the development of the stock exchange in China still could keep a rapid rate in the future. In most advantage countries like U.S. Western Europe and Japan, the total market values of all trading stocks versus the GDP are already equal or more than $100 \%$, while the rate in China was only $31.82 \%$ in 1999 and it is still putting all effort in SOEs (state owned enterprises) reform. In addition the total transactions of stock exchange in China reached 3.14 trillion in 1999, but the online trading only counts less than $1 \%$ of the total values. Comparing with $20 \%$ in U.S. the market for Yestock in China is huge (Yestock materials).

(4) Network and strategic alliances: The main factor of Yestock's success story is the Inherit. Xunda had built a strong business network since it was founded. The business partnerships and customer base have provided the opportunity for it to change its business model-from traditional marketing model to online marketing model. Just a few months after Yestock had been created, it already had more than 50 brokerage companies to join their member community with more than 400,000 registered individual users. Also, Yestock has formed alliances with many telecom companies such as Unicom (Shanghai), Unicom (Zhejiang), China Mobile (Guangdong), etc to develop the mobile-phone stock trading system, it means there are potentially more than 15 million GSM users could be Yestock customers in the future.

(5) Strategic Ownership: According to market observers, this merger could be a win-win solution. On the one hand, Legand as the biggest PC and PDA producer in China, the buyers of its products could be potential customers of Yestock. On the other hand, invest in Yestock can strength Legand's Net strategy in China and helps it moving from hardware sector to soft field. In addition, Yestock can extend Legand's services channel.
For instance, a buyer who buys a PDA from Legand, not means the business is over. When the buyer becomes the customer of Yestock, then Legand can get $40 \%$ of the revenue that this customer brings to Yestock.

(6) The integrated online \& offline business model: The online plus offline business model could be an interesting case for venture capitalism and also it can make customers loyalty.

\section{E. Conclusions}

The development if Yestock is impressive and prospects are bright. The main management issues emerging from this case study are:

(1) First there is the technology selection. The STK technology enables the quick transmission of a lot of data, which is very appropriate in stock trading.

(2) Next is the alliance that Yestock engaged in. Essentially they chose the network-approach, implying that they link up with many different partners. The network provides a wide range of services.

(3) The different business models that users can choose from (e.g. on-line and/or off-line) allow them to make their own choice. Moreover, users can choose from among a number of specific providers, resulting in considerable freedom of choice.

(4) Yestock has benefited from the substantial increase in wealth of persons and organizations, which continues to stimulate the general interest in investment opportunities. The resulting demand for services in this field is enhanced by the rapid development of China's telecommunication and Internet infrastructure.

\section{CASE C-MITSUBISHI (GUANGZHOU) COMPRESSOR CO. LTD.}

\section{A. The Company}

Mitsubishi (Guangzhou) Compressor Co. Ltd. (below refer to Mitsubishi) is a manufacturer that mainly designs and produces air-compressors for industrial use. Facing the strong competition, the company realized that the technology and management innovation is the key success factor and source for it to grow and deal with the increasing competition.

\section{B. The E-technology}

After half a year investigation, this company decided to use the ERP (Enterprise Resource Planning) package that Kaishi Software Co. (below refer to Kaishi) provided. These new technology enables businesses' employees, customers, suppliers and partners to share and integrate important business data across several applications and databases, viewed together on their individual computer desktops via the network.

Kaishi ERP solution includes many functions such as purchase, inventory management, marketing, financial management, production planning and controlling, demand 
forecasting, total quality management, work flow and physic material flow, e-commerce. Each function has its own chart but they also can be integrated together. There are five characteristics of this solution:

- The integration between material flow and money flow

- Suitable for all kinds of manufacturing companies

- The integration between ERP and JIT (Just-in-time)

- Data and information gathering through Internet

- Commerce platform linked by supply and sourcing.

\section{Implementation}

July 221999 , Kaishi sent a team with four members (one project manager, one financial consultant, one physical material flow consultant, and one production management consultant) and two technicians to Mitsubishi to build up the whole system. The installation period is between August 1999 and February 2000. The total investment in this project is 1.57 million RMB (US\$ 0.2 million, excluding the hardware and software that Mitsubishi already had). Based on its own interest and the suggestions from Kaishi and other experts, Mitsubishi chose the IBM 170 as the hardware system, and DB2 and OS/400 as the database and operation system. Also, Kaishi helped Mitsubishi to rebuild and restructure the whole LAN for the ERP project.

\section{Issues}

The implementation of ERP system is a continuous process, and it must be integrated with the growth process within the enterprise. However, during the implementation process, problems usually arise. In the Mitsubishi case, the issues can be summarized as follows:

(1) Process standard and measurement system. The standard and system are the key factors that to lead the success of the ERP project. Mitsubishi and Kaishi had worked together to build up the system, and they had found that the accuracy of the data after the implementation doubled compared with before. Therefore, the management team in this company could much easier make decisions.

(2) ERP integrated financial management. Before applying the ERP system, Mitsubishi was using a financial software package offered by another company; the staff in the financial department were already accustomed to that simple system. The lack of understanding of the new ERP system, therefore, made the implementation of the new system not widely and fully accepted by those staff. During the application process, the project team started to use the method of contrast, and helped them to restructure the whole accounting items' system, explaining to them how to move from traditional accounting management to the real integrated financial management and control. Based on the analysis, the financial department in Mitsubishi reduced half of the items in its old system, and reduced the tasks of its staff largely. As a result, the managers in the financial department had more time for the real financial planning and controlling.
(3) The coding system. From the data point of view, the coding system is also an important factor in implementing an ERP system. It could affect the performance of the whole system. The old coding system was only related to the existing needs and demands of the company. It also should be suitable for further growth and new requirements of the enterprise. In addition, the coding system cannot be very difficult and complicated, and it should be the only system within the company. Mitsubishi and Kaishi worked together to set up a new coding system, and also solved the problem which had existed within the company for a long timethere were several coding systems that Mitsubishi had used.

(4) Training. Training is the key success factor in the ERP implementation process that ensures the managers and employees in the company to understand and accept the system. The way Mitsubishi implemented for the training process is to differ the trainees and programs, which from top management to employee, each will attend a different specified program. Kaishi also helped Mitsubishi to set the exam system to evaluate the training performance. Only those staff who passed the exam could get the certificate for suitable positions. The method ensured the quality of the training program, and reduced the timetable of the implementation process.

(5) Cross-departmental formal meetings. The ERP system implementation requires all functions of the company to fully support it. And the accurate data in every function is the key factor in this process. Each data error in a function or department could cause errors in another function or department. However, it is impossible that the data is always right. Therefore, cross-functions and cross-departments formal meetings are required to ensure the process runs smoothly.

(6) Documents and proofs. Before the ERP system implementation, the company needed to store and keep all original documents and proofs. However, the ERP system had led to reduce many paper works within the company. After the implementation, the documents and proofs have been stored electronically except those papers that are legally necessary (e.g. business contracts, etc).

(7) Management tool. Last but not the least, the ERP system is a tool to offer the management team the possibility to get data and information widely and accurately. However, only after the managers really get the new management ideas and the decision-making know-how, they can define the added value behind those data, and gain competitiveness in the future.

\section{E. Conclusions}

By way of conclusions the following points are identified as the main management issues in implementing etechnology in this manufacturing company: 
a. The company selected a comprehensive e-technology including many functions and constituted a substantial investment.

b. The company emphasized training as a key success factor, since the changes brought about by the new ERP implied rapid and considerable changes for most of the business processes and the employees involved.

c. The company, being typically manufacturing-oriented, has provided itself an appropriate basis upon which it can further build and develop e-business with suppliers and customers.

\section{MANAGEMENT ISSUES}

After presenting the three cases it is time to draw conclusions. All three companies are applying e-technology in China, but there are various differences between the companies described. The first two cases describe typical IT related companies, while the third describes a manufacturing company. Moreover, foreign partners were involved: in a direct way (marketing a European product in China) in the first case and in an indirect way (foreign-Chinese joint venture) in the third case. The role of e-technology also differs in the three cases: adding a service line to the existing business processes (Rayes), developing a new business process (Yestock) and increasing efficiency and effectiveness in business processes (Mitsubishi).

In the application of e-technology it appears that current management theory is still relevant. The major management issues emerging from the case analyses above can be summarized as follows:

a. Cooperation and trust are the key assets in networking. Difference in size between partners does not appear to be a major problem, but the good strategic fit within partners is the heart of a successful cooperation. The careful approach of a local partner is especially important for a company who wants to enter a foreign market.

b. E-technology implies considerable challenges, and the choice of business models plays an important role.

c. Sufficient management attention for details such as training program is needed.

These three issues emphasize that both the strategic (strategic fit, business model) and the operational aspects need to be addressed in managing e-technology in China.

\section{REFERENCES}

$[1]$

[3]

[8]

News 6, Wenhui Bao, June 3, 2000

$\overrightarrow{2000}$

, http://www.chinaview 2000 com.cn

http://www.chinaview.col.com.cn
News1, Renmin Youdian Bao, Dec. 9, 1999 News2, Guangzhou Daily, Dec 21, 1999

News3, People's Daily, Mar. 29, 2000

News4, Economics Daily, Jan. 19, 2000

News5, Zhongguo Shang Bao-Business Daily, Mar. 8, 2000

News 7, How Yestock Wins?, Economics Daily, Aug. 17,

, Marshall, P., \& Wild, M., (1999), Managing Change in the Virtual Organization, in $7^{\text {th }}$ European Conference on Information Systems Proceedings, Vol. 1, pp. 41-53

[11] CNNIC homepage; http:/www.cnnic.net.cn

[12] Das, T.K. \& Teng, B.S., (1997), Sustaining Strategic Alliances: options and guidelines, Journal of General Management, Vol. 22, No. 4, pp. 49-64

[13] Davidow, W. H., \& Malone, M. S., (1992), The Virtual Corporation, New York: Harper Business

[14] Douma, M.U., (1997), Strategic Alliances: fit or failure, Ph.D. Thesis, University of Twente, The Netherlands

[15] Faulkner, David, (1995), International Strategic Alliances: cooperating to compete, McGraw-Hill Book Company, London

[16] Gulati, R., (1998), Alliances and Networks, Strategic management Journal, Vol. 19, pp. 293-317

[17] Killing, J.P. (1983), Strategies for Joint Venture Success, New York, Praeger

[18] Klofsten, M, \& Scharberg, C, 2000, Barriers in Cooperation between small and large Technology based Firms: a Swedish case study, Proceeding for the $8^{\text {th }}$ High-tech small firms conference, Enschede, The Netherlands, 22-23 May, 2000, pp. 139-156

[19] Lu, Peter Weigang (2000) Internet Development in China-an analysis of the CNNIC Survey report

[20] Rayes Homepage: http://www.col.com.cn

[21] Tang L.J., (1999) Create successful Dutch-Chinese Joint Venture, Graduate Thesis, TSM Business School, The Netherlands

[22] Tradeview Homepage: http://www.tradeview.com

[23] Trappey and Trappey (1999), The Internet Economy and E-business Trends and Opportunities in China, Taiwan and Hong Kong

[24] Van der Zee, Han \& Paul Van Wijngaarden, 1999, Strategic Sourcing and Partmerships: challenging scenarios for IT alliances in the network era, Addison Wesley

[25] Wei, Y., (2000), E-commerce in China: developments and issues: Working paper in TDG, University Twente

[26] Whiting, J. T., (1999), "E" Technology: The Real Issue Is Not ERP or E-Commerce, but the Management of IT/Business Convergence, can be accessed from http://www.erpsupersite.com/newsletter/whiting$19991122 . \mathrm{htm}$

[27] Yestock Homepage: http://www.yestock.com 